\title{
Efeito da rugosidade recortada polida no escoamento em modelo de passagem de minério
}

\author{
Effect of slickensided stepped roughness on the \\ flow through an ore pass model
}

\section{Amilton Bernardino da Silva Filho \\ Professor do Instituto Federal de Minas Gerais (IFMG - Ouro Preto) \\ E-mail: amiltonfh@yahoo.com.br \\ José Margarida da Silva \\ Eng. de Minas, Dr. pela EE/UFMG, \\ Professor Adjunto da Escola de Minas/UFOP \\ E-mail:jms@demin.ufop.br}

\section{Adilson Curi}

Eng. de Minas, Dr. pelo IST, Portugal, Professor Associado da Escola de Minas/UFOP, Programa de Pós-

Graduação em Engenharia Mineral Departamento de Engenharia de Minas/EM/UFOP

E-mail: curi@demin.ufop.br

\section{Resumo}

O principal objetivo desse trabalho é analisar o comportamento do fluxo de material fragmentado em passagens de minério com paredes rugosas. Nesse estudo, um modelo físico de passagem de minério em escala reduzida foi utilizado para observar o efeito da rugosidade sobre o fluxo. A inserção de placas de madeira nas paredes internas do modelo foi realizada de modo a simular as rugosidades do tipo recortada polida. A escolha desse modelo de rugosidade, selecionado a partir dos padrões adotados internacionalmente pela ISRM (Sociedade Internacional de Mecânica de Rochas), foi devido à sua grande similaridade com o padrão de rugosidade encontrado em passagens de minério reais construídas por explosivos. Os resultados dos ensaios realizados no modelo revelaram que as rugosidades do tipo recortada polida provocam uma queda significativa de vazão em relação aos ensaios realizados em paredes lisas. Também foi observada, para esse modelo de rugosidade, a ocorrência de arcos mecânicos, fluxo em funil e fluxo turbulento.

Palavras-chave: Rugosidade, fluxo por gravidade, passagem de minério, modelos físicos, material fragmentado, lavra subterrânea.

\begin{abstract}
The main objective of this paper is to analyze the behavior of bulk material flow in rough-surface ore passes. A physical model of an ore pass in reduced scale has been used to observe the effect of the roughness on the flow. The insertion of wooden plates on the internal walls of the model was carried out in order to simulate the slickensided stepped roughness. This model of roughness has been selected from the standards adopted internationally by the ISRM due to its similarity with the actual roughness found in ore passes built using explosives. The tests showed that the slickensided stepped roughness causes a significant decrease of the flow rate when compared to the tests carried out with smooth walls. The tests'results also indicated the occurrence of mechanical arches, funnel flow and turbulent flow.
\end{abstract}

Keywords: Roughness, gravity flow, ore pass, physical model, bulk material, underground mining. 


\section{Introdução}

As passagens de minério presentes em muitas minas subterrâneas são o principal meio de transferir verticalmente o minério desmontado para silos de minério e pontos de carregamento em subsolo. Assim, esses condutos exercem uma importância primordial em relação ao escoamento do minério no ambiente subterrâneo. Por isso, essas unidades de transporte por gravidade devem ser adequadamente projetadas de modo que não haja impedimento ao fluxo de minério. Também são regiões de potencial acidente nas minas subterrâneas.

A rugosidade das paredes das passagens é um fator de grande relevância quando se trata de impedimento ao fluxo. Ela pode se originar de características naturais do maciço (presença de descontinuidades) ou do método construtivo da passagem (corte mecânico, desmonte por explosivo ou, ainda, acréscimo de tubos partidos em elevação). Apesar disso, na literatura, não são encontrados trabalhos referentes à influência das rugosidades da parede das passagens de minério sobre o fluxo de material fragmentado. Os poucos artigos existentes sobre as passagens de minério apenas tratam de questões de projeto, tais como pontos de descarga, pontos de carregamento, ramificações, joelhos, impacto no portão de descarga, entre outros (Goodwill et al., 1999; Blight \& Haak, 1994; Hambley, 1987; Aytaman, 1960; Peele, 1941; Joughin \& Stacey, 2004, Kvapil, 1965; Beus et al., 2001).

\section{Passagem de minério}

As passagens de minério são muito freqüentes nas minas que utilizam o método de realce em subníveis (sublevel stoping) e, também, nas minas que adotam os métodos de abatimento ou ainda enchimento. Apresentam-se em grande número nas minas onde a lavra é executada através de vários níveis de extração em corpos de minério com forte mergulho. Em corpos de minério com mergulho raso, as passagens de minério são pouco freqüentes, sendo aliadas, geralmente, ao sistema de transporte (Hambley, 1987). Embora a designação passagem de minério esteja referenciada à transferência de minério, esses sistemas de transporte podem ser utilizados para qualquer tipo de rocha fragmentada.

Com relação à configuração, as passagens de minério apresentam-se verticais ou fortemente inclinadas, unidirecionais ou podendo dispor de curvas ou joelhos (dog-legs) na sua porção inferior. Também podem ter, em sua extremidade inferior, região de descarga, um dispositivo de controle de fluxo denominado de chute ou portão de descarga. Na extremidade superior, região de carregamento, geralmente são instalados dispositivos de bitolamento como telas e escalpes. Os dispositivos de bitolamento têm o objetivo de controlar a máxima dimensão dos fragmentos que escoarão pela passagem, reduzindo assim, a probabilidade de ocorrência de obstruções.

A passagem de minério pode ser construída através de explosivos ou por ação mecânica ou, ainda, com o acréscimo de tubos partidos em elevação, na medida da progressão da lavra. A utilização do explosivo na construção das passagens de minério produz paredes com rugosidades significativas, que podem prejudicar o fluxo de minério. Segundo Hambley (1987), os principais problemas que afetam o desempenho das passagens são os entupimentos (blockages), devido à formação de arcos coesivos, e bloqueios (hang-ups), devido à formação de arcos mecânicos. A diferença entre entupimentos e bloqueios está relacionada à localização da obstrução. Um bloqueio (hang-up) é definido como um impedimento ao fluxo no ponto de carregamento ou na zona de trânsito da passagem, enquanto um entupimento (blockage) é uma obstrução localizada próximo à saída da passagem, ou seja, na zona de descarga.

Os arcos mecânicos se desenvolvem como uma conseqüência do apri- sionamento de fragmentos de grandes dimensões no interior das passagens, originando, assim, uma obstrução com uma configuração estável (Figura 1a). Segundo Hambley (1987), esse tipo de obstrução também ocorre devido a abruptas mudanças na geometria da passagem, citando, como exemplo, a presença de joelhos e encurvamento na porção inferior das passagens. Esse fenômeno foi observado no estudo de Silva (2005). A probabilidade de formação de arcos mecânicos depende da porcentagem de fragmentos grandes presentes no material manuseado, do tamanho das partículas em relação à dimensão da passagem e dimensão da saída, da forma dos fragmentos e do perfil de velocidade através do fluxo de minério.

Os arcos coesivos, como mostra a Figura 1b, requerem que o material fragmentado tenha uma proporção significativa de partículas finas. Com relação às passagens de minério, as partículas são consideradas finas, quando sua dimensão está abaixo de $0,07 \mathrm{~mm}$. A porcentagem de finos presentes no material fragmentado, que leva a ocorrência de arcos coesivos, ainda não está bem estabelecida (Hadjigeorgiou \& Lessard, 2007).

Um dos primeiros passos para a desobstrução de passagens de minério é localizar a posição da obstrução. Depois de determinada a localização, deve-se determinar se a obstrução trata-se de um arco mecânico ou arco coesivo. A técnica mais confiável, para remoção de arcos coesivos, é a utilização de um fluxo de água a alta pressão. Esse método, dependendo da quantidade de água utilizada no desentupimento, poderá originar grandes avalanches de lama, como já verificado em mina brasileira de extração de ouro. Outro método utilizado, na remoção de arcos coesivos, é a inserção de ferramentas manuais (alavancas ou extensas barras de ferro). $\mathrm{O}$ método de inserção de ferramentas manuais oferece grandes riscos à integridade física dos operadores destinados à remoção por esse método, principalmente em passagens totalmente verticais. 
O método usual de destruir um arco mecânico é inserir explosivo na passagem através de um furo, realizado com essa finalidade, acima do portão. Então o explosivo é iniciado e o arco é destruído.

O fluxo livre nas passagens de minério minimiza os vários problemas operacionais e de segurança relacionados à restituição do fluxo. Diversas recomendações práticas para assegurar o fluxo livre em passagens de minério, representadas pela razão entre a dimensão característica da passagem (D) e a dimensão do maior fragmento (d), são encontradas na literatura (vide Figura 2). Um grande inconveniente apresentado por essas recomendações está relacionado com a grande variação da razão D/d na definição de fluxo livre. Além disso, outras informações relevantes ao fluxo de minério nas passagens não são consideradas, tais como inclinação da passagem, rugosidade das paredes, propriedades físicas dos fragmentos, etc. Segundo Silva e Gripp (2006), o domínio do fluxo livre nas passagens é geralmente limitado pela linha que representa uma escavação cuja seção transversal é da ordem de 4 a 6 vezes o tamanho do maior fragmento.

\section{Materiais e métodos}

O modelo físico (Figura 3a) utilizado nessa pesquisa, para a verificação do efeito da rugosidade em passagens de minério, foi o modelo da pesquisa de Silva (2005). Esse modelo, na escala 1:20, foi definido a partir das dimensões do corpo de minério da mina Baltar do grupo Votorantim (Votorantim, SP), sendo os valores reais dos parâmetros geométricos das escavações e do corpo de minério arbitrados. A mina Baltar utiliza o método de realce em subníveis (sublevel stoping) na extração de calcário, em que o minério apresenta um forte mergulho, contatos regulares e grandes dimensões. As adaptações para simular as rugosidades são apresentadas na Figura 3b e na Figura 3c.

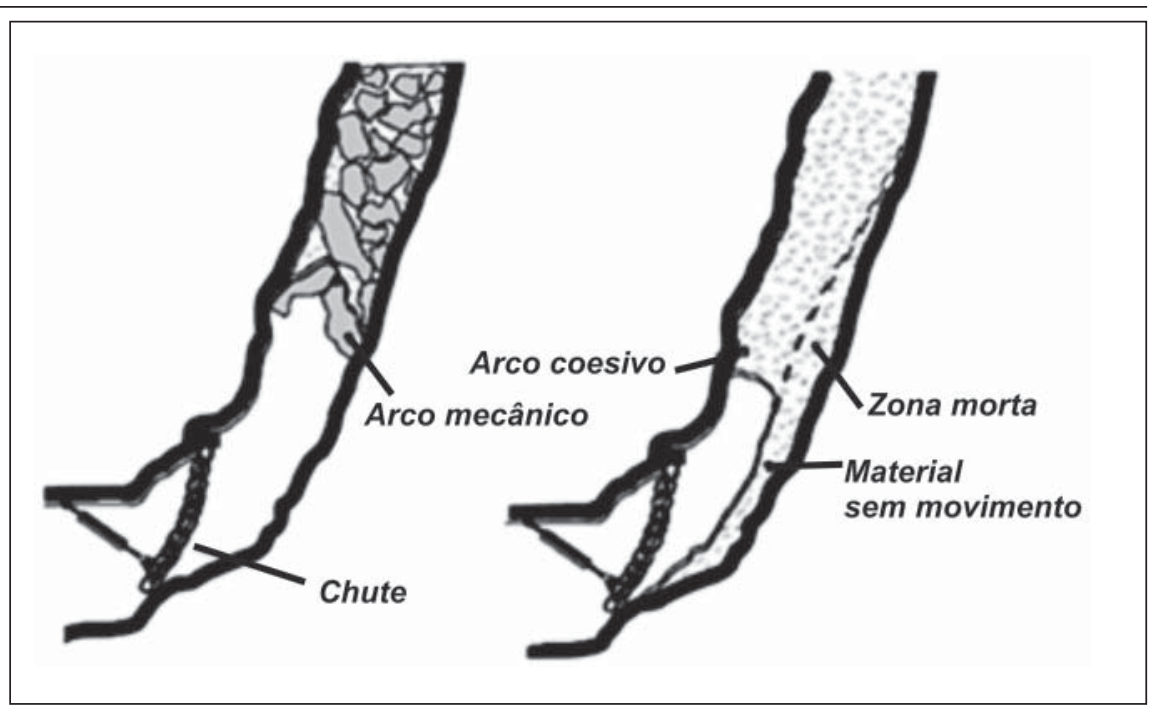

Figura 1 - Obstruções em passagens de minério devido a: a) arco mecânico, b) arco coesivo (Hadjigeorgiou \& Lessard, 2007).

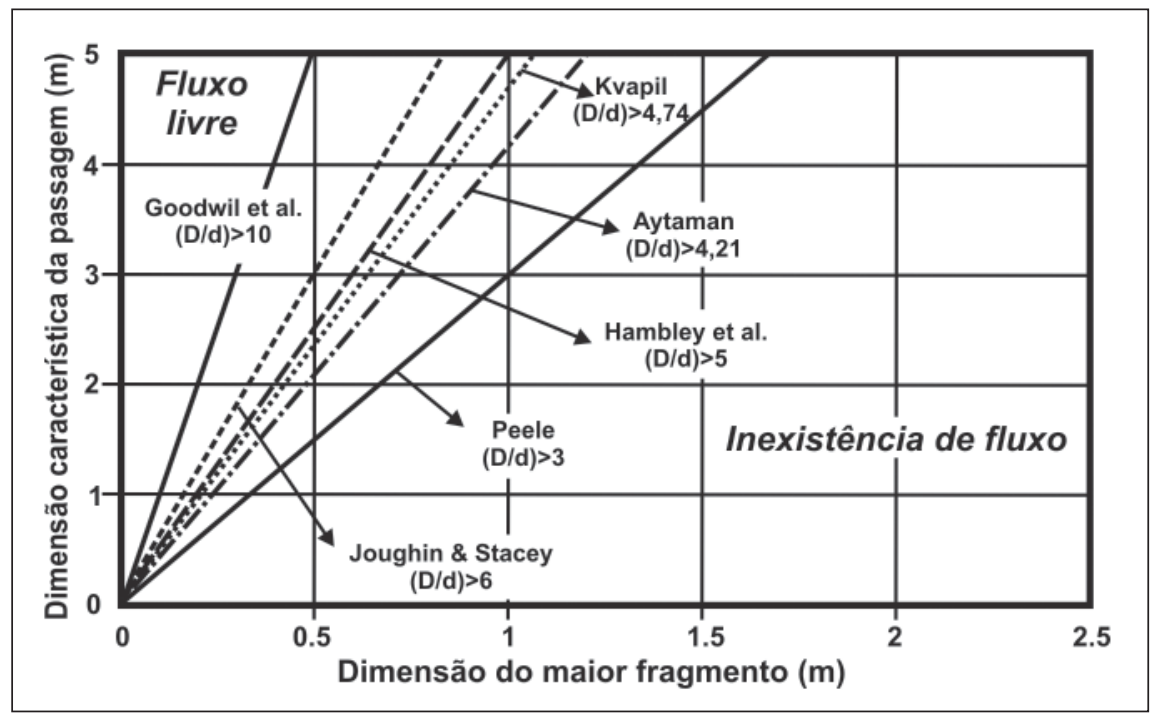

Figura 2 - Recomendações práticas baseadas na razão D/d para assegurar o fluxo livre em passagens de minério (Hadjigeorgiou \& Lessard, 2007).

As dimensões do modelo (e respectiva dimensão real, na escala 1:20) são:

- Largura do corpo de minério - 2,1m (42m).

- Altura do corpo de minério - 3,9m (78m).

- Seção da passagem de minério - 0,12m x 0,16m.

- Espaçamento entre travessas - 0,6m (12m).

- Espaçamento entre subníveis - 0,75m (15m).

- Seção das galerias - altura de 0,275m (5,5m) por largura de 0,2m (4m).

Placas de madeira (denominadas comercialmente de compensado) foram distribuídas no interior do modelo de forma a simular as rugosidades (Figura 3b) encontradas nas paredes de passagens de minério reais decorrentes do avanço por explosivos. O critério do arranjo das rugosidades, no interior do modelo, foi basea- 


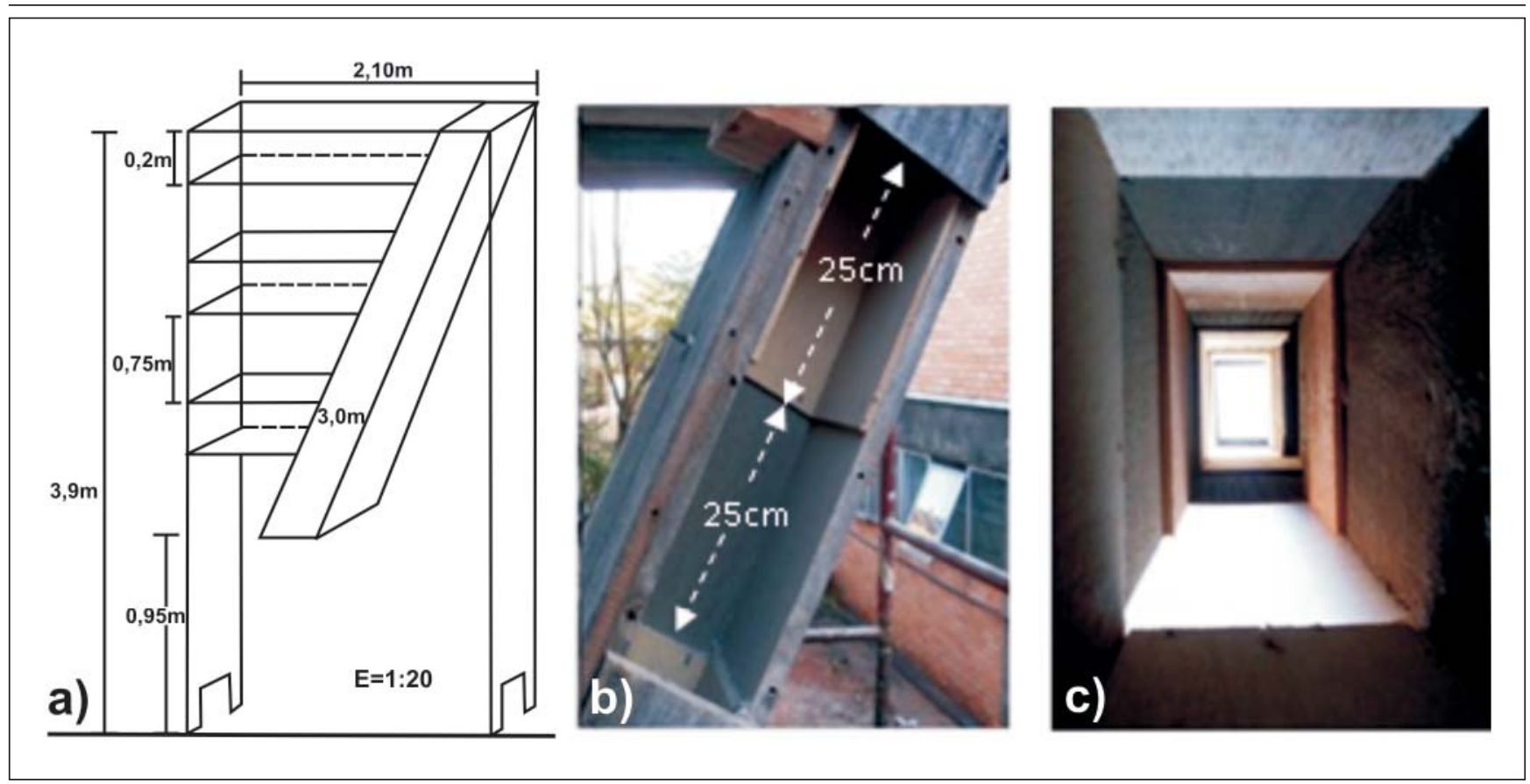

Figura 3 - Modelo físico de passagem de minério: a) representação esquemática do modelo físico; b) comprimento das rugosidades e espaçamento entre as rugosidades no interior do modelo físico; c) vista superior da distribuição das rugosidades no interior do modelo físico.

do nos padrões (Figura 4) adotados internacionalmente pela ISRM (Sociedade Internacional de Mecânica de Rochas) . O perfil selecionado foi da rugosidade recortada polida que se assemelha às rugosidades nas paredes de passagens de minério reais.

Cada placa de madeira, no interior do modelo, possui $25 \mathrm{~cm}$ de comprimento, $0,5 \mathrm{~cm}$ de espessura e largura coincidente com a largura da parede do modelo. Aárea ocupada pelas placas de madeira, em termos de seção transversal, representa um total de, aproximadamente, $10 \%$ da área transversal total do modelo.

Nos ensaios realizados em modelo físico de passagem, foi utilizado, como material fragmentado, a brita de gnaisse em três faixas granulométricas (denominadas comercialmente de brita 0 , brita 1 e brita 2). Foram testadas duas variações da inclinação da passagem $\left(90^{\circ}\right.$ e $\left.60^{\circ}\right)$, três níveis da coluna de material (0,9m; 2,0m e 3,0m). Foi observada a ocorrência de fenômenos diversos, com os ensaios sempre documentados, sendo também medida a vazão aparente de descarga. Os resultados obtidos nessa pesquisa foram confrontados com os resultados do trabalho de Silva (2005) para o fluxo em paredes lisas.

A preparação do ensaio em modelo físico de passagem de minério constou de estabelecimento da inclinação do modelo (com determinação do ângulo com bússola e clinômetro de disco) e da colocação eventual de marcadores. A determinação da velocidade de fluxo foi realizada através da medição

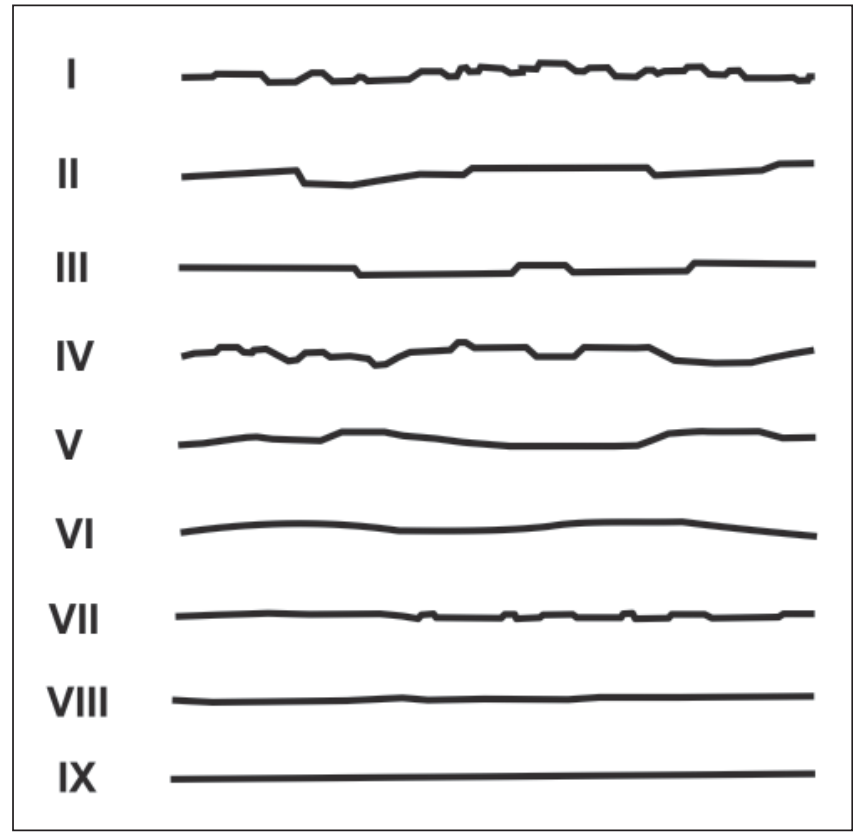

Figura 4 - Classificação das rugosidades: I) recortada irregular, II) recortada uniforme, III) recortada polida, IV) ondulada irregular, V) ondulada uniforme, $\mathrm{VI}$ ) ondulada polida, $\mathrm{VII}$ ) plana irregular, VIII) plana uniforme e IX) plana polida (ISRM, 1981 apud Brady \& Brown, 1985).

da massa (em balança digital, com precisão de $0,04 \mathrm{~kg}$ ) e do tempo de fluxo (cronômetro digital, com precisão de 0,01s). Conhecidas a massa específica aparente do material e a seção de descarga, foram determinadas a vazão aparente de descarga e a velocidade de fluxo do material no modelo de passagem. 
Na realização dos ensaios no modelo físico de passagem de minério, a seguinte seqüência de trabalho foi obedecida:

1) Programação geral dos ensaios.

2) Programação de cada ensaio, com ensaio preliminar para definição dos tempos de coleta.

3) Alimentação do material no modelo.

4) Abertura da saída.

5) Documentação fotográfica de etapas do processo, considerando-se as colunas de enchimento de material no modelo.

6) Coleta do material passante, medição de sua massa e determinação da vazão; documentação fotográfica do material retido (geometria formada para cada material ensaiado).

O comportamento interno do fluxo no modelo foi detectado pela introdução de marcadores coloridos, colocados em regiões de fácil visualização no modelo físico, com gravação de imagens e observação da seqüência na descarga de material no modelo. Para marcadores foram utilizados os próprios materiais de ensaio. Os materiais utilizados como marcadores foram pintados de cores diferentes sendo, durante o enchimento no modelo, colocados em camadas de, aproximadamente, $10 \mathrm{~cm}$ de altura. Foram utilizadas, em cada ensaio, duas camadas coloridas (dispostas no topo próximo ao acrílico) intercaladas por uma camada também de $10 \mathrm{~cm}$ de material normal. Através de observações do movimento dos marcadores, foi possível determinar a formação de fluxo em funil e diferenças significativas na velocidade do fluxo.

Os arranjos dos fragmentos durante o escoamento foram observados através de documentação fotográfica e da observação visual das colisões de partículas.

\section{Resultados e discussão}

Os testes realizados com a brita 2 de gnaisse no modelo a $90^{\circ}$ e $60^{\circ}$ de inclinação evidenciam a ação das irregularidades da superfície do conduto sobre o escoamento. Em todas as três camadas de enchimento utilizadas nos testes, houve ocorrência de $100 \%$ de arcos mecânicos tornando o escoamento inviável. Os testes mostraram que, nessa granulometria, as partículas de brita próximas à parede são retidas pelas quinas das irregularidades. A paralisação do movimento das partículas próximo às quinas leva também à paralisação das outras partículas do fluxo devido ao intertravamento entre os contatos dos fragmentos. Geralmente, a formação dos arcos inicia-se imediatamente próximo à abertura de saída do modelo físico tão logo se inicia o fluxo (Figura 5a), confirmando a maior probabilidade de ocorrência nessa região, descrita pela literatura.

A utilização de marcadores para as britas 0 e 1 com inclinação de $90^{\circ}$ indicou a formação de fluxo em funil (Figura 5b). A ocorrência desse modelo de fluxo foi devido a uma diferença significativa entre a velocidade do fluxo do material próximo à parede e o fluxo central. $\mathrm{O}$ fluxo central escoa muito mais rapidamente do que o fluxo de partículas próximas às paredes. Essa diferença torna-se significativa devido às irregularidades presentes na parede do modelo. Para todos os testes com utilização de marcadores, foram utilizadas colunas de enchimento de $3 \mathrm{~m}$ com o modelo a $90^{\circ}$ e $60^{\circ}$ de inclinação.

Para a brita 0 e a brita 1 , a $60^{\circ}$ de inclinação, verificou-se a formação de um fluxo turbulento (Figura 5c). Esse fenômeno ocorre devido à transposição do fluxo sobre as quinas das irregularidades situadas na parede superior do modelo. Essa transposição, aliada ao peso da coluna sobre a rugosidade, faz com que o fluxo se reduza, na região de transposição, a um canal de fluxo com velocidade intensa. A maior velocidade do

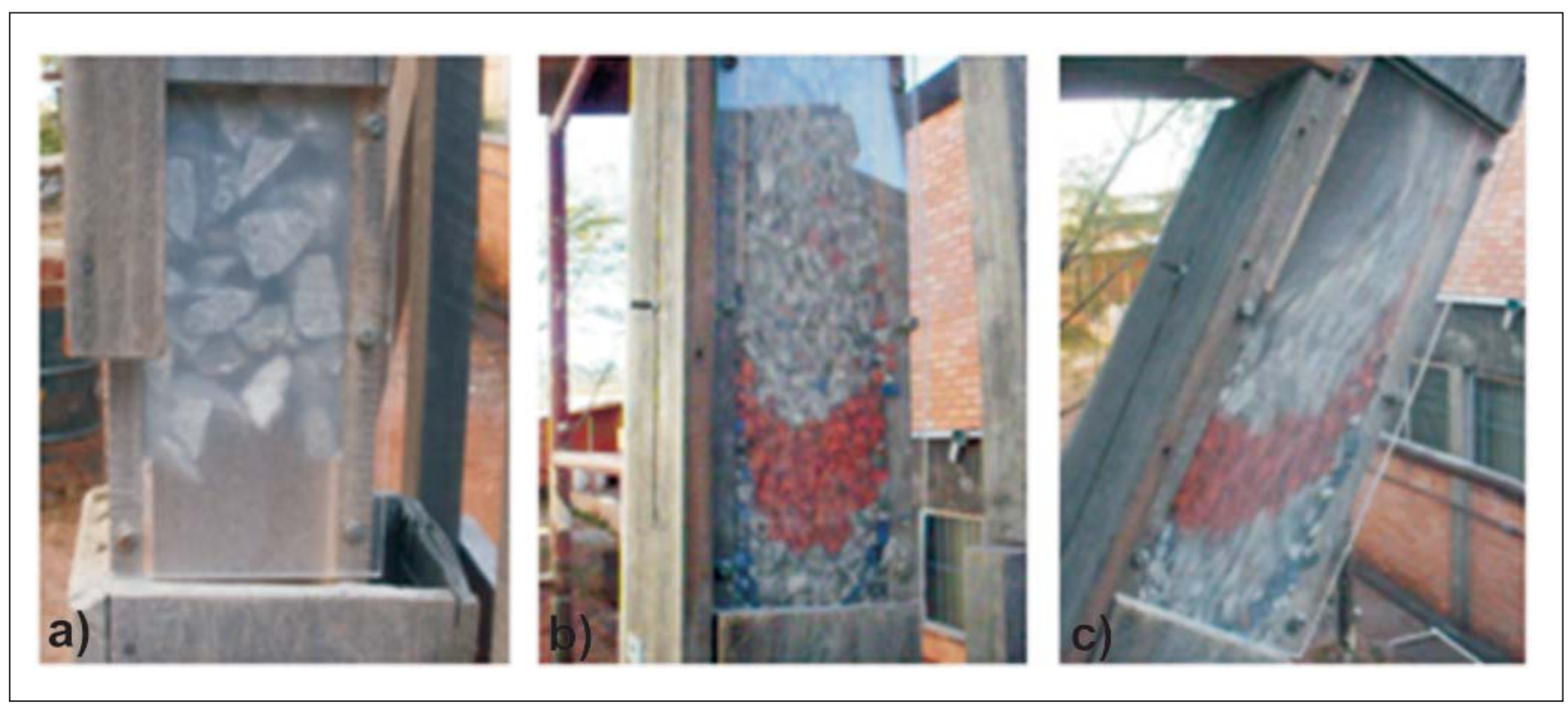

Figura 5 - Efeitos observados nos ensaios: a) arcos mecânicos, b) fluxo em funil e c) fluxo turbulento. 
fluxo nesse turbilhão faz com que as partículas se choquem violentamente entre si e contra a parede inferior do modelo de passagem de minério. Observando o mesmo efeito para a brita 1 e para a brita 0 de gnaisse, foi possível constatar que, quanto menor a granulometria das partículas, maior é a velocidade do fluxo turbulento e intensidades dos choques. Esse fluxo turbulento poderá, em casos reais, intensificar o grau e o número de irregularidades nas paredes das passagens, produzindo, assim, cavidades significativas.

Analisando comparativamente as vazões dos ensaios em paredes lisas e rugosas para a brita 0 e para a brita 1 , nas condições estabelecidas de inclinação e coluna de enchimento, pode-se observar similaridade entre os escoamentos. A diferença entre os escoamentos, em paredes lisas e rugosas, está basicamente relacionada à queda acentuada de vazão entre 42 e $60 \%$. Essa queda foi mais intensa para os escoamentos com o modelo na vertical.

\section{Conclusões}

Em cada um dos processos de construção das passagens de minério em minas subterrâneas, padrões diferentes de rugosidade podem ser apresentados pela parede do conduto. Nesse trabalho, entre os padrões sugeridos pela ISRM, foi testado o perfil de rugosidade do tipo recortada polida devido a sua semelhança com as rugosidades encontradas em passagens de minério construídas por desmonte por explosivos.

As conclusões referentes aos ensaios no modelo físico de passagem de minério, para os materiais utilizados e para as variações realizadas dos parâmetros envolvidos, indicam que:

- A presença da rugosidade recortada polida provoca uma queda significativa de vazão comparando os ensaios em paredes lisas com os ensaios em paredes rugosas.

- A rugosidade recortada polida intensifica a freqüência de arcos mecânicos e acentua diferenças na velocidade de fluxo.

- A rugosidade recortada polida leva à ocorrência de fluxo em funil e de fluxo turbulento.

Além do estudo apresentado, existem, ainda, vários questionamentos a serem respondidos. Como sugestão para trabalhos posteriores, propõe-se:
- Estabelecimento de equações de fluxo para o escoamento de material fragmentado em passagens de minério.

- Influência da forma da seção transversal de passagens de minério sobre o fluxo de material fragmentado em paredes rugosas.

- Variação dos padrões de rugosidade no modelo físico e também do volume que essas rugosidades ocupam na seção.

- Influência da proporção de partículas finas e da umidade sobre o fluxo de material fragmentado em passagens de minério com paredes rugosas.

\section{Referências bibliográficas}

AYTAMAN, V. Causes of hanging in ore chutes and its solution. Canadian Mining Journal, n. 81, p.77-81, 1969.

BRADY, B. H. G., BROWN, E. T. Rock Mechanics for Underground Mining. London: George Allen \& Unwin, 1985. 527p.

BEUS, M. J., PARISEAU, W. G., STEWART, M., IVERSON, S. Design of ore passes. In: HUSTRULID, W., BULLOCK, R. (eds). Underground mining methods: engineering fundamentals and international case studies, Littleton, CO. Society of Mining, Metallurgy and Exploration, 2001. p.627-634.

BLIGHT, G. E., HAAK, B. G. A test on model underground ore passes. Bulk Solids Handling, v. 14, n. 1, p.77-81, jan/mar 1994.

GOODWILL, D. J., CRAIG, D. A., CABREJOS, F. Ore pass design for reliable flow. Bulk Solids Handling, v. 19, n. 1, p.13-21, 1999.

HADJIGEORGIOU, J., LESSARD, J. F. Numerical investigations of ore pass hang-up phenomena. International Journal of Rock Mechanics and Mining Sciences, v. 44, p. 820-834, 2007.

HAMBLEY, D. F. Design of ore pass systems for underground mines. CIM Bulletin, v. 80, n. 897, p.25-30, 1987.

JOUGHIN, A., STACEY, T. R. The behaviour of ore passes in deep level tabular mines. In: SECOND INTERNATIONAL SEMINAR ON DEEP AND HIGH STRESS, Saimm, 2004, p.395-411.

KVAPIL, R. Gravity flow of granular materials in hoppers and bins in mines - part II: coarse materials. International Journal of Rock Mechanics and Mining Sciences \& Geomechanics Abstracts, v. 2, p. 277-304, 1965.

PEELE, R. Mining Engineers' Handbook. (3. ed.). New York: John Wiley and Sons, 1941. v.1.

SILVA, J. M., GRIPP, M. F. A. Fluxo de material fragmentado em passagem de minério nas minas subterrâneas: a prática corrente. REM - Revista Escola de Minas, v. 59, n. 3, p.307-310, 2006.

SILVA, J. M. Estudo do fluxo de material fragmentado na mineração subterrânea com o uso de modelos físicos. Belo Horizonte: Curso de Pós-Graduação em Engenharia Metalúrgica e de Minas, UFMG, 2005. 181 p. (Tese de Doutorado).

Artigo recebido em 17/06/2009 e aprovado em 21/07/2010.

\section{A REM tem novo endereço: FUNDAÇÃO GORCEIX - REM Rua Carlos Walter Marinho Campos, 57 - Vila Itacolomy 35400-000 - Ouro Preto - MG}

